Pacific Journal of Mathematic 


\title{
CONTINUOUS SPECTRA AND UNITARY \\ EQUIVALENCE
}

\author{
C. R. Putnam
}

1. Introduction. In the differential equation

$$
\left(p x^{\prime}\right)^{\prime}+(\lambda+f(t)) x=0,
$$

let $\lambda$ denote a real parameter and let $p(t)(>0)$ and $f(t)$ be continuous real-valued functions on $0 \leqq t<\infty$. Suppose that (1) is of the limit-point type, so that (1) and a linear homogeneous boundary condition

$$
x(0) \cos \alpha+x^{\prime}(0) \sin \alpha=0, \quad 0 \leqq \alpha<\pi,
$$

determine a boundary value problem with a spectrum $S=S_{\alpha}$ on the half-line $0 \leqq t<\infty$; cf. [7]. The continuous spectrum $C_{\alpha}$ (if it exists) is determined by a continuous monotone nondecreasing basis function $\rho_{\alpha}(\lambda)$. It is known that the set of cluster points, $S^{\prime}$, of $S_{\alpha}$ is independent of $\alpha,[7, \mathrm{p} .251]$; the question as to whether the corresponding assertion for $C_{a}$ is also true was raised by Weyl $[7,7.252]$ but is still undecided.

Consider the self-adjoint operators $H_{\alpha}=\int \lambda d E_{\alpha}(\lambda)$ (all of which are extensions of the same symmetric operator) belonging to the various boundary value problems determined by $(1)$ and $\left(2_{\alpha}\right)$; cf. for example, [2]. The object of this note is to shown that any two $H_{\alpha}$ possessing purely continuous (hence, in view of the above remark concerning $S^{\prime}$, necessarily identical) spectra are unitarily equivalent, at least if certain conditions concerning the nature of the sets $C_{\alpha}$ and the basis functions $\rho_{\alpha}(\lambda)$ are met. In fact there will be proved the following.

TheOREM $(*)$. Suppose that there exist two (distinct) values $\alpha_{1}$ and $\alpha_{2}\left(0 \leqq \alpha_{k}<\pi\right)$ such that, for each of the two boundary value problems determined by (1) and $\left(2_{\alpha k}\right)$, the following three conditions are satisfied:

(i) $S_{\alpha k} \neq(-\infty, \infty)$,

(ii) the point spectrum is empty, and

(iii) $\rho_{\alpha k}(\lambda)$ is absolutely continuous. Then $H_{\alpha 1}$ and $H_{\alpha^{2}}$ are unitarily equivalent.

The condition (i) of $\left({ }^{*}\right)$ surely holds if, for instance, $f$ is bounded or even bounded from below on $0 \leqq t<\infty$. It should be noted however that every (real) $\lambda$ belongs to an $S_{\alpha}$ for some $\alpha$ (depending on $\lambda$ ); [1].

For other results on the continuous spectra of boundory value pro-

Received April, 1956. This work was supported by the National Science Foundation research grant NSF-G481. 
blems with absolutely continuous basis functions (on certain intervals), see [4].

The proof of $\left(^{*}\right)$ in $\S 2$ will depend upon the following result of $\mathrm{M}$. Rosenblum [5] concerning perturbations of self-adjoint operators: Let the self-adjoint operators $A_{k}=\int \lambda d E(\lambda)$ (for $k=1,2,3$ ) satisfy $A_{1}-A_{2}=A_{3}$. Suppose, in addition, that $A_{3}$ is completely continuous and such that $\int|\lambda| d E_{3}(\lambda)$ has a finite trace while $\left(E_{1} x, y\right)$ and $\left(E_{2} x, y\right)$ are absolutely continuous functions of $\lambda$ for arbitrary $x$ and $y$ in Hilbert space. Then $A_{1}$ and $A_{2}$ are unitarily equivalent.

2. Proof of $\left(^{*}\right)$. In the sequel, the index $\alpha_{k}$ will be replaced by $k$. It is clear from the assumptions that there exists some real value $\lambda=\lambda^{*}$ not belonging to $S_{k}$ for $k=1,2$. Consequently, since $f(t)$ can be replaced in (1) by $f(t)+\lambda^{*}$, it can be supposed without loss of generality that $\lambda=0$ is not in either of the sets $S_{k}$. Then the operators $H_{k}^{-1}$, where

$$
H_{k}^{-1}=\int_{\lambda}^{-1} d E_{k}(\lambda)=\int d F_{k}(\lambda) \quad\left(F_{k}(\lambda)=E_{k}\left(\lambda^{-1}\right)\right)
$$

are bounded, self-adjoint integral operators with kernels $G_{k}(s, t)$ on $0 \leqq s, t<\infty$; cf. for example, [2], [7]. Furthermore,

$$
G_{1}(s, t)-G_{2}(s, t)=c g(s) g(t),
$$

where $c$ denotes a constant and $g(t)$ is a function of class $L^{2}[0, \infty)$; cf. [7, p. 251]. Thus $\left(H_{1}^{-1}-H_{2}^{-1}\right) x$ is a multiple of $g$ for every element $x$ of class $L^{2}[0, \infty)$. Hence $H_{1}^{-1}-H_{2}^{-2}$ is a multiple of a one-dimensional projection operator ; in particular, $H_{\bar{\tau}}^{-}-H_{2}^{-1}$, corresponding to $A_{3}$, satisfies the trace condition on that operator mentioned at the end of $\S 1$.

In view of the assumptions (ii) and (iii) of $\left(^{*}\right)$, it follows from the formulas relating the basis functions $\rho_{k}(\lambda)$ to the projections $E_{k}(\lambda)$ (cf., for example, [2]) that $\|E(\lambda) x\|$ is an absolutely continuous function of $\lambda$ for every $x$ in the Hilbert space; therefore $\left(E_{k}(\lambda) x, y\right)$, hence also $\left(F_{k}(\lambda) x, y\right)$, is absolutely continuous for every pair $x, y$ of this space. According to the above mentioned theorem of Rosenblum, it now follows that the operators $H_{k}^{-1}$ (hence also the $H_{k}$ ) are unitarily equivalent, and the proof of $\left(^{*}\right)$ is now complete.

3. Consider the special case of (1) in which $f \equiv 0$. It is readily seen that there are no eigenvalues for either of the boundary value problems determined by $x^{\prime \prime}+\lambda x=0$ and the respective boundary conditions $x(0)=0$ and $x^{\prime}(0)=0$. (These boundary conditions correspond to $\alpha=0$, 
$\pi / 2$ in $\left(2^{\alpha}\right)$; in a somewhat more general connection, cf. [3, p. 792]). Thus, in each case, there is a purely continuous spectrum consisting of the half-line $0 \leqq \lambda<\infty$. Moreover, the basis functions, which, in this instance, are even known explicitly [6, p. 59] are absolutely continuous. Consequently, Theorem $\left({ }^{*}\right)$ is applicable and shows that the self-adjoint operators belonging to the above mentioned boundary value problems are unitarily equivalent.

\section{REFERENCE}

1. P. Hartman and A. Wintner, An oscillation theorem for continuous spectra, Proc. Nat. Acad. Sci., 33 (1947), 376-379.

2. K. Kodaira, The eigenvalue problem for ordinary differential equations of the second order and Heisenberg's theory of S-matrices, Amer. J. Math., 71 (1949), 921-945.

3. C. R. Putnam, An application of spectral theory to a singular calculus of variations problem, Amer. J. Math., 70 (1948), 780-803.

4. $\quad$, On the continuous spectra of singular boundary value problems, Can. J. Math., 6 (1954), 420-426.

5. M. Rosenblum, Perturbations of the continuous spectrum and unitary equivalence, Technical Report No. 12, for Office of Ordnance Research, Department of Mathematics, University of California, December 1955.

6. E. C. Titchmarsh, Eigenfunction expansions associated with second-order differential equations (Oxford, 1946).

7. H. Weyl, Ueber gewöhnliche Differentialgleichungen mit Singularitäten und die zugehörigen Entwicklungen willkürlicher Funktionen, Math. Ann., 68 (1910), 222-269. 



\section{PACIFIC JOURNAL OF MATHEMATICS}

EDITORS

H. L. ROYDEN

Stanford University

Stanford, California

R. A. Beaumont

University of Washington

Seattle 5 , Washington
A. R. Whiteman

University of Southern California

Los Angeles 7, California

E. G. Straus

University of California

Los Angeles 24, California

\section{ASSOCIATE EDITORS}
E. F. BECKENBACH
C. E. BURGESS
M. HALL
E. HEWITT
A. HORN
V. GANAPATHY IYER
R. D. JAMES
M. S. KNEBELMAN

L. NACHBIN

I. NIVEN

G. SZEKERES

T. G. OSTROM

M. M. SCHIFFER
F. WOLF

K. YOSIDA

\section{SUPPORTING INSTITUTIONS}

UNIVERSITY OF BRITISH COLUMBIA

CALIFORNIA INSTITUTE OF TECHNOLOGY

UNIVERSITY OF CALIFORNIA

MONTANA STATE UNIVERSITY

UNIVERSITY OF NEVADA

OREGON STATE COLLEGE

UNIVERSITY OF OREGON

UNIVERSITY OF SOUTHERN CALIFORNIA

\author{
STANFORD UNIVERSITY \\ UNIVERSITY OF UTAH \\ WASHINGTON STATE COLLEGE \\ UNIVERSITY OF WASHINGTON \\ AMERICAN MATHEMATICAL SOCIETY \\ CALIFORNIA RESEARCH CORPORATION \\ HUGHES AIRCRAFT COMPANY \\ THE RAMO-WOOLDRIDGE CORPORATION
}




\section{Pacific Journal of Mathematics}

\section{Vol. 7, No. $1 \quad$ January, 1957}

Richard Davis Anderson, Zero-dimensional compact groups of

homeomorphisms ................................... 797

Hans-Joachim Bremermann, Holomorphic functionals and complex

convexity in Banach spaces........................... 811

Hugh D. Brunk, G. M. Ewing and W. R. Utz, Minimizing integrals in

certain classes of monotone functions ................. 833

Philip David, Uniqueness theory for asymptotic expansions in general

regions ...................................... 849

Paul Erdős and Harold Nathaniel Shapiro, On the least primitive root of a

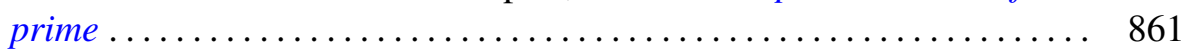

Watson Bryan Fulks, Regular regions for the heat equation ........... 867

William Robert Gaffey, A real inversion formula for a class of bilateral

Laplace transforms ................................ 879

Ronald Kay Getoor, On characteristic functions of Banach space valued random variables ................................. 885

Louis Guttman, Some inequalities between latent roots and minimax (maximin) elements of real matrices ...................... 897

Frank Harary, The number of dissimilar supergraphs of a linear graph .... 903

Edwin Hewitt and Herbert S. Zuckerman, Structure theory for a class of convolution algebras .................................. 913

Amnon Jakimovski, Some Tauberian theorems . . . . . . . . . . . . . . . . . 943

C. T. Rajagopal, Simplified proofs of "Some Tauberian theorems" of Jakimovski................................

Paul Joseph Kelly, A congruence theorem for trees ................. 961

Robert Forbes McNaughton, Jr., On the measure of normal formulas...... 969

Richard Scott Pierce, Distributivity in Boolean algebras .............. 983

Calvin R. Putnam, Continuous spectra and unitary equivalence ......... 993

Marvin Rosenblum, Perturbation of the continuous spectrum and unitary

equivalence................................... 997

V. N. Singh, Certain generalized hypergeometric identities of the

Rogers-Ramanujan type.......................

Peter Swerling, Families of transformations in the function spaces $H^{p} \ldots \ldots 1015$ 